For numbered affiliations see end of article.

mohana@who.int Cite this as: BMJ 2021;372:n719 http://dx.doi.org/10.1136/bmj.n719 Published: 31 March 2021

\title{
ADOLESCENT WELLBEING
}

\section{Uniting for adolescents in covid-19 and beyond}

Helen Clark, ${ }^{1}$ Tedros Adhanom Ghebreyesus, ${ }^{2}$ Anne-Birgitte Albrectsen, ${ }^{3}$ Jorge Alcocer, ${ }^{4}$ Errol Alden, ${ }^{5}$ Audrey Azoulay, ${ }^{6}$ Saul Billingsley, ${ }^{7}$ Robert W Blum, ${ }^{8}$ Rajesh Bhushan, ${ }^{9}$ Winnie Byanyima, ${ }^{10}$ Rodrigo Alberto Carazo Zeledon, ${ }^{11}$ Annabel Erulkar, ${ }^{12}$ Lucy Fagan, ${ }^{13}$ Adesegun Fatusi, ${ }^{14}$ Henrietta H Fore, ${ }^{15}$ Stefan Germann, ${ }^{16}$ Karina Gould, ${ }^{17}$ David Imbago, ${ }^{18}$ Jessica Kahn, ${ }^{19}$ Natalia Kanem, ${ }^{20}$ Uhuru Kenyatta, ${ }^{21}$ Zoleka Mandela, ${ }^{22,23}$ Phumzile Mlambo-Ngcuka, ${ }^{24}$ Wendy Morton, ${ }^{25}$ George Patton, ${ }^{26}$ Gogontlejang Phaladi, ${ }^{27}$ Susan M Sawyer, ${ }^{28}$ Kevin Watkins, ${ }^{29}$ Jayathma Wickramanayake, ${ }^{30}$ Anshu Mohan

The current generation of adolescents is the largest ever, with 1.2 billion people aged 10-19 years worldwide. They are at risk of inheriting a world blighted by climate change and scarred by covid-19. Although they have been spared the most severe direct effects of the pandemic, the indirect effects on their wellbeing are devastating. ${ }^{12}$ Many adolescents are experiencing disruptions to their access to health, education, and preventive services, and the pandemic has further exacerbated inequalities. ${ }^{1}$ The pandemic is changing everything for adolescents and youth, as they experience the transitions that will define their future wellbeing: completing education, moving into the workforce, and forming life partnerships.

Even before covid-19, adolescents and young adults faced multiple and intersecting challenges to their wellbeing. These challenges include social injustice and inequalities (such as those related to gender, gender identity, and inclusion), insufficient social protection, inadequate mental health, poor sexual and reproductive health, and an inability to exercise their rights resulting in unintended pregnancies, HIV, and all forms of malnutrition. Adolescents and young adults are also experiencing a crisis of connection to family, community, and society, with increasing numbers living on the streets or dropping out of school. ${ }^{34}$ Between 2003 and 2015, development assistance for adolescent health accounted for only $1.6 \%$ of total development assistance for health, 5 despite a third of the total global burden of disease estimated to have roots in adolescence. ${ }^{6}$ Mental health problems affect $10-20 \%$ of adolescents, and many more experience symptoms that diminish wellbeing. ${ }^{7}$ Furthermore, this is the age at which the gender inequalities that underlie and pose major barriers to wellbeing emerge clearly and is when programmes can transform these inequalities.

When adolescents move into young adulthood, many face unemployment or unstable employment, and girls in many countries are often expected to take on the burden of unpaid care work at home. In 2017, 34\% of young women and $10 \%$ of young men aged $15-24$ years were not in employment, education, or training, with more pronounced disparities in northern Africa and southern Asia. ${ }^{6} 8$ Even among employed adolescents and young adults, an increasing proportion have poor job security, variable weekly earnings, and minimal or no health or social security coverage. $^{8}$
These examples show that, as a global community, we have paid insufficient attention to the multidimensional and intersectional nature of adolescent wellbeing and the importance of the transition to young adulthood. People have too often wrongly assumed that, as long as adolescents are given a formal education and access to basic healthcare, their wellbeing will take care of itself. Efforts to support adolescent wellbeing have tended to be piecemeal, with different sectors focusing exclusively on their own areas of expertise and sometimes losing sight of the overall objective of promoting adolescents' rights and wellbeing.

In 2019, for a more concerted and collaborative approach to adolescents' wellbeing, an unprecedented coalition of governments, United Nations agencies, non-governmental organisations, and academic institutions-working closely with adolescents and young people-committed to a call to action for adolescent wellbeing. ${ }^{9}$ Underpinning this call to action is a new agreed definition and conceptual framework for adolescent wellbeing to inform policies and programming. ${ }^{10}$ The framework emphasises the importance of integrating five interconnected domains in adolescent programming: good health and optimum nutrition; connectedness, positive values, and contribution to society; safety and a supportive environment; learning, competence, education, skills, and employability; and agency and resilience.

We invite everyone-decision makers, policy makers, civil society, service providers, educators, donors, innovators, and, most importantly, adolescents themselves-to support this call to action. Together, we can ensure that it results in concrete policies, integrated programmes, and sustained investments for adolescent wellbeing.

A global summit on adolescent wellbeing in 2023 was a key recommendation of the call to action. The summit will provide a powerful platform to drive forward our collective efforts for a gender transformative, multifaceted, and multisectoral response to adolescent wellbeing, with a focus on strengthening financing, policies, services, and accountability. The summit aims to contribute to ensuring that today's adolescents are empowered to solve the problems they are inheriting. 
Adolescents, youth, and youth led organisations are at the heart of this initiative and will continue to be so. But we all have a part to play in achieving these goals if we are to deliver a more equitable and inclusive world for this and future generations.

\section{AUTHOR AFFILIATIONS}

1

Partnership for Maternal, Newborn, and Child Health (PMNCH), World Health Organization, 20 Avenue Appia, 1211 Geneva 27, Switzerland

2

World Health Organization, Switzerland

3 Plan International, UK

4 Government of Mexico, Mexico

5 International Pediatric Association, USA

6

Unesco, France

FIA Foundation, UK

Department of Population, Family, and Reproductive Health, Johns Hopkins Bloomberg School of Public Health, USA

9 Government of India, India

10

UNAIDS, Switzerland

United Nations

12

Population Council, Ethiopia

13

UN Major Group for Children and Youth, UK

14

University of Medical Sciences, Nigeria

15

Unicef, USA

16

Fondation Botnar, Switzerland

17

Government of Canada, Canada

18

International Youth Health Organization, Ecuador

19 Society for Adolescent Health and Medicine, USA

20

United Nations Population Fund (UNFPA), USA

Republic of Kenya

Child Health Initiative, UK

23

Zoleka Mandela Foundation, South Africa

24

UN Women, USA

25

Foreign, Commonwealth, and Development Office, Government of the United Kingdom, UK

26

Centre for Adolescent Health and the Murdoch Children's Research Institute, University of Melbourne, Australia

27

Pillar of Hope Project, Botswana

28

International Association of Adolescent Health, Australia

29

Save the Children, UK

30

Office of the Secretary General's Envoy on Youth, United Nations, USA
Competing interests: SB is an employee (executive director) of the FIA Foundation (UK registered charity No 1088670), a trustee of International Road Assessment Programme (registered charity No 1140357), and a member of the steering committee of the United Nations Road Safety Fund. LF declares a non-financial interest as member of the World Health Organization Global Action for Measurement of Adolescent Health advisory group on adolescent health measurement. JK is president of the Society for Adolescent Health and Medicine (unpaid) and receives funding from the US National Institutes of Health (NIH). She was previously an investigator in primarily NIH funded research studies (vaccine clinical trials) that received funding from Merck for the costs of vaccine and antibody testing, though she and her institution did not receive any funding. ZM is founder of the Zoleka Mandela Foundation and global ambassador of the Child Health Initiative. All other authors declare no competing interests

1 The Lancet. Generation coronavirus? Lancet 2020;395. doi: 10.1016/S0140-6736(20)31445-8 pmid: 32593326

2 Ford T, John A, Gunnell D. Mental health of children and young people during pandemic. BMJ 2021;372:. doi: 10.1136/bmj.n614 pmid: 33692087

3 Organisation for Economic Cooperation and Development. HC3.1 homeless population. 2020 https://www.oecd.org/els/family/HC3-1-Homeless-population.pdf.

4 Unicef, Unesco Institute for Statistics. Monitoring education participation: framework for monitoring children and adolescents who are out of school or at risk of dropping out. 2016. http://uis.unesco.org/sites/default/files/documents/monitoring-education-participation.pdf

5 Li Z, Li M, Patton GC, Lu C. Global development assistance for adolescent health from 2003 to 2015. JAMA Netw Open 2018;1:e181072.

doi: 10.1001/jamanetworkopen.2018.1072 pmid: 30646101

6 World Health Organization. Adolescent health epidemiology. https://www.who.int/maternal_child_adolescent/epidemiology/adolescence/en/.

7 Wesselhoeft R, Sørensen MJ, Heiervang ER, Bilenberg N. Subthreshold depression in children and adolescents - a systematic review. J Affect Disord 2013;151:-22. doi: 10.1016/j.jad.2013.06.010 pmid: 23856281

8 International Labour Organization. Where do the world's NEETs live? 2020. https://www.ilo.org/global/about-the-ilo/multimedia/maps-and-charts/enhanced/WCMS_598674/lang--en/index.htm.

9 Child Health Initiative. PMNCH, Plan international, UNFPA Unicef, WHO UN Major Group for Children and Youth. Adolescents 2030: a call to action for adolescent wellbeing. https://www.adolescents2030.org/

10 Ross DA, Hinton R, Melles-Brewer M, etal. Adolescent wellbeing: a definition and conceptua framework. J Adolesc Health 2020;67:-6. doi: 10.1016/j.jadohealth.2020.06.042 pmid: 32800426

This is an Open Access article distributed under the terms of the Creative Commons Attribution IGO License (https://creativecommons.org/licenses/by-nc/3.0/igo/), which permits use, distribution, and reproduction for non-commercial purposes in any medium, provided the original work is properly cited. 